International Journal of Current Advanced Research

ISSN: O: 2319-6475, ISSN: P: 2319 - 6505, Impact Factor: SJIF: 5.995

Available Online at www.journalijcar.org

Volume 6; Issue 3; March 2017; Page No. 2460-2464

DOI: http://dx.doi.org/10.24327/ijcar.2017.2464.0028

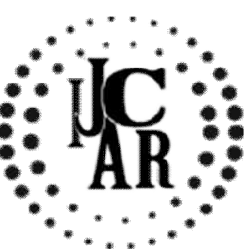

Research Article

\title{
PEER EVALUATION RUBRIC CRITERIA DEVELOPED BY UNIVERSITY STUDENTS FOR PROBLEM-BASED LEARNING
}

\author{
Shin-Il Han
}

Department of Education, College of Education, Sungkyunkwan University, Seoul, Korea

\begin{tabular}{|c|c|}
\hline A R T I C L E & A 1 \\
\hline Article History: & \multirow{8}{*}{$\begin{array}{l}\text { The rubric is an effective instrument for making assessment criteria explicit, and for } \\
\text { helping ensure fairness in grading. The use of rubrics for peer evaluation in cooperative } \\
\text { class environments can offer the same benefits. This study analyzed student-developed } \\
\text { criteria for a peer evaluation rubric in order to determine the elements that university } \\
\text { students valued most in the cooperative activity of Problem-Based Learning. Nineteen } \\
\text { university students participated in the study, and the major tool for categorizing the } \\
\text { characteristics of peer evaluation was a modified version of both the Teamwork Skill } \\
\text { Inventory and the Category-based peer evaluation framework. Findings indicated that the } \\
\text { category of Attends to Teamwork, Motivation, Responsibility, and Time Management was } \\
\text { the most frequently applied category for the peer evaluation rubric related to team activity. } \\
\text { The study also provided additional details about the criteria utilized in all seven categories } \\
\text { developed for this peer evaluation rubric. }\end{array}$} \\
\hline eceived $10^{\text {th }}$ December, 2016 & \\
\hline ise & \\
\hline Februa & \\
\hline Publis & \\
\hline Kye Words: & \\
\hline & \\
\hline & \\
\hline
\end{tabular}

Copyright $₫ 2017$ Shin-Il Han. This is an open access article distributed under the Creative Commons Attribution License, which permits unrestricted use, distribution, and reproduction in any medium, provided the original work is properly cited.

\section{INTRODUCTION}

Fair evaluation is one of the most important commitments in teaching, and is generally not an issue when an assessment is based on quantitative and objective data, such as multiple choice tests or attendance checks. Things change, however, when qualitative and subjective assessment is a major component of evaluating student achievement. Students often complain about unfair evaluation results based on the qualitative assessment of an individual; this does not occur in classes using multiple choice tests. Similar issues arise in classes utilizing cooperative learning methods, such as Problem-Based Learning (PBL), which may employ peer evaluation as one of the grading methods.

Peer evaluation is most often utilized when assessing student contributions to a team activity. Felchikov (1986) utilized peer assessment to help promote competence, confidence, creativity, coping, and cooperation in his projects. Ohland, Laton, Loughry, and Yuhasz (2005) found that peer raters often provided better, more accurate feedback, suggesting that instructors should carefully evaluate the benefits of using peer evaluations when determining students' grades. A study by DeNisi, Randolph, and Blencoe (1983) revealed that peers made finer distinctions among different aspects of performance than did supervisors, and feedback from peers was more effective than supervisor ratings.

*Corresponding author: Shin-Il Han

Department of Education, College of Education, Sungkyunkwan University, Seoul, Korea
In addition, Strachan and Wilcox (1996) reported that students perceived peer assessment to be fair, valuable, enjoyable, and helpful in developing transferable skills in research, collaboration, and communication.

In peer evaluation, team members judge their peers on specific traits, behaviors, and achievements (Kramer, 1990); and the forms of peer evaluation are usually provided by instructors in a survey form utilizing a rubric. The rubric is an assessment tool that makes explicit what is being assessed, lists the criteria to be evaluated for different degrees of quality, and provides a rating scale to differentiate among these degrees (Powell, 2015). Evaluation is the process by which assessment results are designated as excellent, good, acceptable, below expectations, and so forth, depending on the quality indicators chosen, and descriptions of these indicators are provided (Kinne, Hasenbank, \& Coffey, 2014). Use of a rubric helps to ensure fairness in grading, and brings a level of objectivity to what might otherwise be viewed as subjective evaluation (Diab \&Balaa, 2011; Reddy \& Angrade, 2010). In addition, it improves consistency and accuracy of grading, provides finer differentiation between assignments, facilitates processes for feedback and promoting selfreflection and engagement with assessment criteria, and promotes assessment for learning as well as of learning (Hack, 2014). Jonsson \& Svingby (2007) observed that many studies have demonstrated rubric effectiveness by showing improvement in both the internal consistency of raters, interrater reliability, and measurement of reliability. It has also been reported that using a rubric as a frame of reference for 
exercises in self- or peer evaluation has a positive influence on student learning (Panadero \& Jonsson, 2013).

Nevertheless, a ready-made version of a peer evaluation rubric developed for all of an instructor's classes may not be suitable for a specific team in a cooperative class, as team members are different in each and every class. For this reason, students participating in cooperative learning may want to have their own unique peer evaluation criteria for judging various group members and their characteristics, behaviors, and achievements.

This study provided students with the opportunity to develop their own peer evaluation rubric and examined the rubrics developed to determine what criteria students most value in the team activity of PBL. Study results provide informed knowledge about the factors that university students consider most important in teamwork, and also ideas for university instructors as they consider tools for better evaluating students in cooperative learning environments.

\section{METHODOLOGY}

\section{Participants}

Nineteen students participated in this study; each student was enrolled in one or two cooperative learning classes utilizing PBL. Study participants included more male (58\%) than female students, and more seniors (74\%) than freshmen, sophomores, and juniors. Descriptive data of the sample is shown in Table 1.

Table 1 Descriptive Statistics of Study Sample

\begin{tabular}{ccccccc}
\hline & & & \multicolumn{2}{c}{ School Year } & \multirow{2}{*}{ Total } \\
& & Sophomore & Junior & Senior & & \\
\hline Gender & Male & 0 & 3 & 8 & 11 & $(57.9 \%)$ \\
& Female & 2 & 0 & 6 & 8 & $(42.1 \%)$ \\
Total & $2(10.5 \%)$ & $3(15.8 \%)$ & $14(73.7 \%)$ & $19(100.00 \%)$ \\
\hline
\end{tabular}

\section{Data Collection and Analysis}

Every participating student was informed that he or she would be asked to evaluate his or her peers after completion of the PBL activity. For purposes of this study, students were asked to develop their own criteria for the peer evaluation rubric, with the requirement that the number of criteria for each category evaluated should be limited to five. They were asked to submit the results of the peer evaluation within a week after completing the activity.

All criteria that students developed and utilized were collected, analyzed, and categorized. Categorization was based on a rubric of an adapted version that utilized both the Teamwork Skill Inventory (TSI) of Strom \& Strom (2011) and the Category-based peer evaluation framework of Lejk \& Wyvill (2001). The final version of the peer evaluation rubric, a hybrid mixture largely derived from the TSI, was implemented for peer evaluation. It is provided below. Student criteria for the peer evaluation rubric were eventually categorized based on this framework.

- Category 1 Attends to Teamwork, Motivation, Responsibility, Time Management implies: (1)Shows acceptable attendance for team meetings, (2)Arrives on time for scheduled team meetings, (3) Stays focused on the task during teamwork, (4)Fulfills individual role assigned by the team, (5)Does fair share of work expected of everyone, (6) Accepts and reliably completes fair share of work by the required time

- Category 2 Seeks and Shares Information implies:

(1)Admits when uncertain about what to do, (2)Asks questions that promote understanding of lessons, (3) Assists others by explaining or reviewing lessons, (4) Contributes reading materials for the team, (5) Refers to reading materials during discussions

- Category 3 Communicates with Teammates implies:

(1) Shares feelings, ideas, and opinions, (2)Speaks clearly, with acceptable and informed vocabulary, (3) Limits length of comments so others can speak, (4) Listens to everyone and respects differing viewpoints, (5) Recognizes individual contributions

- Category 4 Thinks Critically and Creatively implies: (1) Evaluates evidence for differing opinions, (2) Uses logic to challenge team's thinking, (3)Thinks carefully before reaching conclusions, (4) Combines and builds on the ideas of others, 5) Offers new ways of looking at problems, (6) Solves problems, originates new ideas, initiates team decisions

- Category 5 Works Well with the Team, Adaptable implies: (1)Receives criticism in a non-defensive manner, (2)Avoids using put-downs or blaming others, (3) Compromises to deal with conflict, (4)Keeps trying when a task becomes difficult, (5) Expresses hope about team success, (6)Demonstrates positive attitude, encouragement, and support of team decisions, desire for consensus

- Category 6 Technical Skills implies: (1)Provides technical solutions to problems, ability to create designs on own initiative

- Category 7 Other implies: (1)Other

\section{Findings}

As seen in Table 2, a frequency distribution of criteria for the peer evaluation rubric revealed that Category $1-$ Attends to Teamwork, Motivation, Responsibility, Time Managementscored highest in students' selection for the peer evaluation criteria, with 44.8 percent of the criteria chosen for peer evaluation. Close examination of the frequency distribution showed that all of the participants developed more than one criterion related to Category 1 . It is also worthwhile to note that the number of students who developed three or more category 1 of the five categories was seven of the 19 total participants. The second most frequent selection for peer evaluation criteria was Category 4, Thinks Critically and Creatively $(16.8 \%)$, followed by Category 3 , Communicates with Teammates $(11.6 \%)$. Category 4 evaluates the degree of peer students' critical and creative thinking (and originality), while category 3 includes the meaning of communication with peer members.

By way of contrast, the lowest percentage of criteria selected in the peer evaluation rubric was Category 2, Seeks and Shares Information, with team members. Category 7, Other, included peer evaluation criteria that could not be assigned to Categories 1 through 6. Criteria in this category included peer students' constancy, time investment in teamwork, diligence, 
preparation for group activity, concentration during meetings, and contribution to teamwork. Category 7 comprised nearly 10 percent of all the criteria of the peer evaluation rubric.

Table 2 Frequency Distribution of Criteria of Peer Evaluation Rubric by Category

\begin{tabular}{|c|c|c|c|c|c|c|c|}
\hline & Category & Category & y Category & Category & Category & Category & Category \\
\hline Student ID & 1 & 2 & 3 & 4 & 5 & 6 & 7 \\
\hline A & 2 & - & 1 & 1 & - & - & 1 \\
\hline B & 2 & - & - & 2 & 1 & - & - \\
\hline $\mathrm{C}$ & 2 & - & - & 2 & 1 & - & - \\
\hline D & 3 & - & 1 & 1 & - & - & - \\
\hline E & 2 & 1 & 1 & - & - & 1 & - \\
\hline $\mathrm{F}$ & 2 & - & 1 & 1 & - & 1 & - \\
\hline G & 3 & - & - & - & - & - & 2 \\
\hline $\mathrm{H}$ & 1 & 1 & 1 & - & - & 2 & - \\
\hline I & 3 & - & - & - & 1 & 1 & - \\
\hline $\mathrm{J}$ & 3 & - & - & - & - & - & 2 \\
\hline $\mathrm{K}$ & 2 & 1 & 1 & 1 & - & - & - \\
\hline $\mathrm{L}$ & 1 & - & - & 2 & 1 & 1 & - \\
\hline $\mathrm{M}$ & 2 & - & 1 & 1 & 1 & - & - \\
\hline $\mathrm{N}$ & 2 & - & 1 & 1 & 1 & - & - \\
\hline $\mathrm{O}$ & 1 & - & 1 & 2 & - & - & 1 \\
\hline $\mathrm{P}$ & 3 & - & - & 1 & - & - & 1 \\
\hline Q & 4 & - & 1 & - & - & - & - \\
\hline $\mathrm{R}$ & 3 & - & 1 & 1 & - & - & - \\
\hline $\mathrm{S}$ & 2 & 1 & - & - & - & - & 2 \\
\hline $\operatorname{Total}(\mathrm{n}=19)$ & $43(44.8 \%)$ & $4(4.2 \%)$ & $11(11.6 \%)$ & $16(16.8 \%)$ & $6(6.3 \%)$ & $6(6.3 \%)$ & $9(9.5 \%)$ \\
\hline
\end{tabular}

Analysis of criteria of the major six categories of the peer evaluation rubric, except Category 7 , Other, showed variety of contents related to the designated categories. The detailed criteria are described, along with frequency of occurrence, in Figures 1 through 6. Criteria of Category 1 (Attends to Teamwork/ Motivation/Responsibility/Time Management) numbered seven, and included fair division of individual roles, attendance, assignment, punctuality, sincerity, positive attitude, participation, and other (Figure 1).

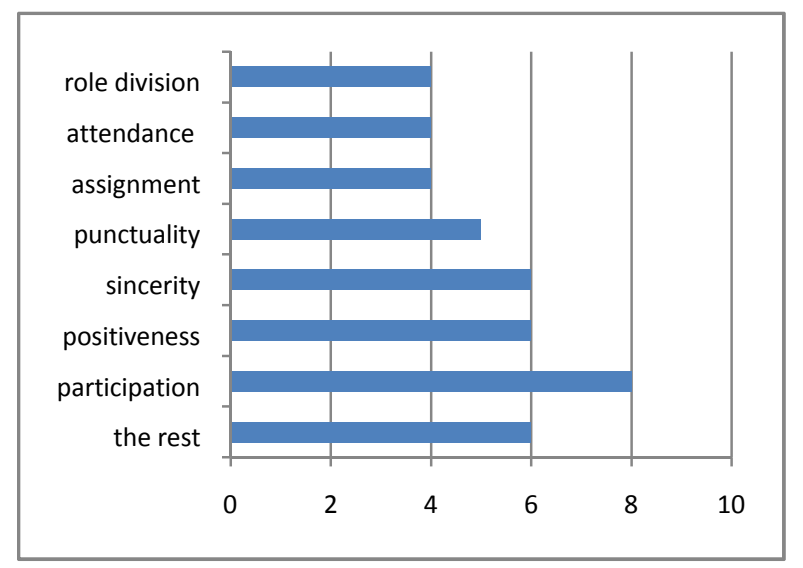

Figure 1 Category 1 Criteria of Peer Evaluation Rubric

The criterion related to "participation" took the largest number, with eight. The criteria grouped in the Rest of Category 1 included responsibility, ability, and enthusiasm. Category 2 (Seeks and Shares Information) was comprised of two criteria, research and literature review, and students chose the category with the least number (Figure 2). Category 3 (Communicates with Teammates - Figure 3) had two major criteria and the Rest. The two criteria were communication and active comment; The Rest included comprehension, feedback, listening courteously, opinion, sympathy, and understanding ability. Category 4 (Thinks Critically and Creatively) included four criteria and the Rest (Figure 4). The four identified criteria were quality of work, initiative, ideas, and creativity. And, the Rest of Category 4 included leadership, logicality, and theory investigation. Category 5
(Works Well with the Team/Adaptable) had just one criteria, cooperation, and the Rest. The Rest included conflict resolve, moderateness (aggressive or not aggressive), team player, and thoughtfulness (Figure 5). The last category, Category 6(Technical Skills), had two sub-categories which include software skills and presentation preparation (Figure 6).

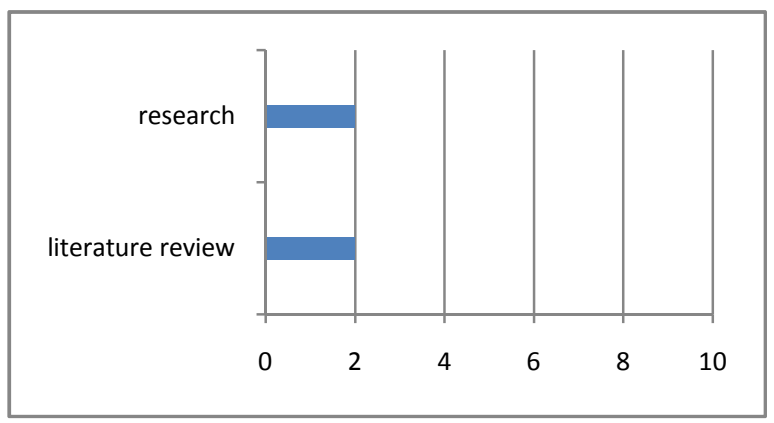

Figure 2 Category 2 Criteria of Peer Evaluation Rubric

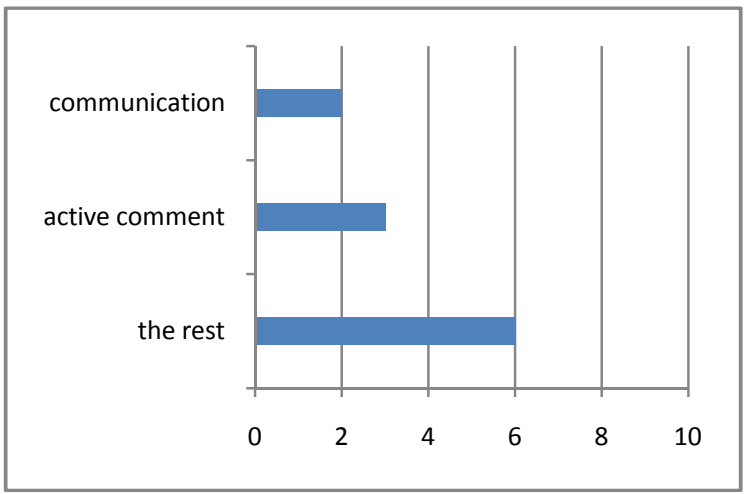

Figure 3 Category 3 Criteria of Peer Evaluation Rubric

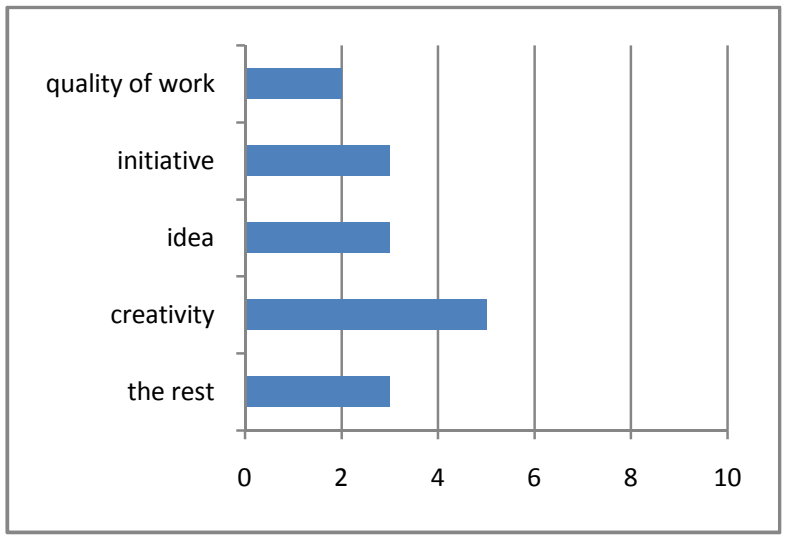

Figure 4 Category 4 Criteria of Peer Evaluation Rubric

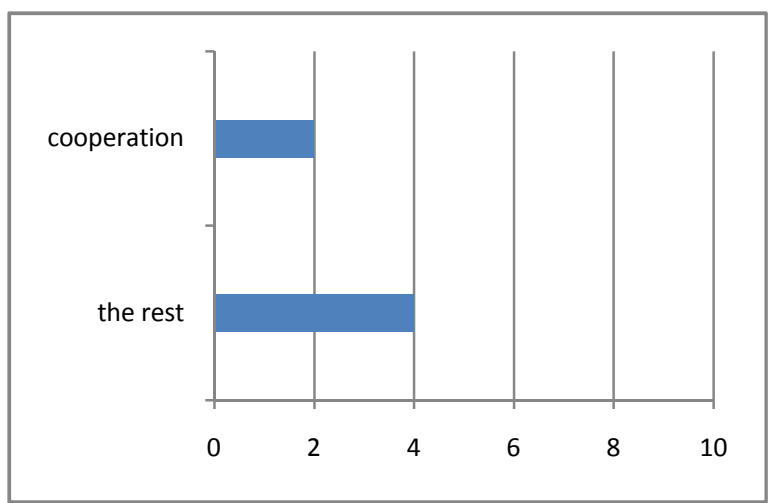

Figure 5 Category 5 Criteria of Peer Evaluation Rubric 


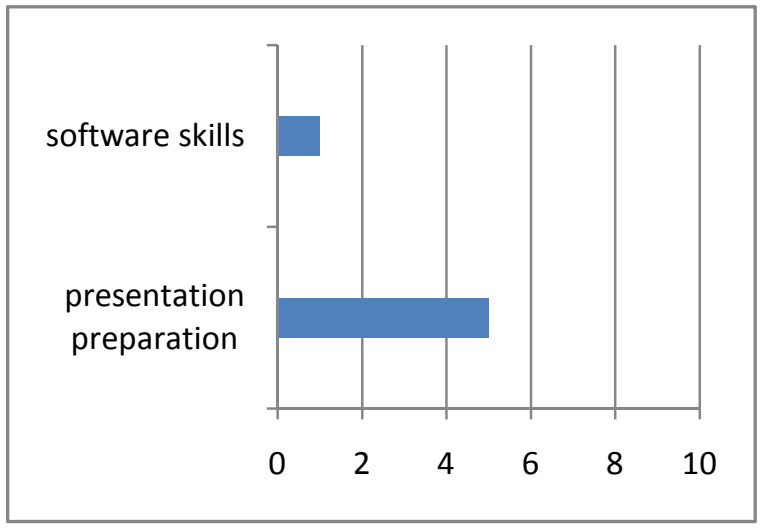

Figure 6 Category 6 Criteria of Peer Evaluation Rubric

\section{CONCLUSION}

The purpose of this study was to analyze university students' self-developed criteria for a peer evaluation rubric in order to determine the criteria they value most in team activity. Nineteen university students participated, and the criteria they developed were analyzed by a combined and modified version of both the Teamwork Skill Inventory (TSI) of Strom \& Strom (2011) and the Category-based peer evaluation framework of Lejk \& Wyvill (2001).

Study results revealed that the students' most preferred criteria category involved attention to teamwork, motivation, responsibility, and effective time management. Furthermore, the percentage of students who used three or more criteria in this category of five reached almost 40 . A closer examination of the category revealed that the concrete terminologies of the criteria they developed for this category included fair division of individual roles, regular attendance, assignment, punctuality, sincerity, positive attitude, and participation, and that among these, criteria related to participation took the largest number. The result implies that students committed to teamwork value positive attitudes and behaviors ("passion") towards group activities, including prompt and regular attendance and behaving in a responsible, sincere, and fair manner. The second most preferred category was the degree of peer students' critical and creative thinking, with the criteria of quality of work, initiative, ideas, creativity, logicality, and theory investigation. This result informs us that students value peers' creativity and originality, as these characteristics improve the quality of the end product, which leads to a higher final grade or achievement score. The thirdhighest ranked category was that of communication with peer members. In this category, students developed criteria such as active comment, comprehension, feedback, listening courteously, sharing opinions, sympathy, and understanding. These criteria indicate that participants in team activities may feel more engaged when their peers give feedback and share opinions in a courteous and sympathetic manner.

These study findings, which revealed the significance of passion for teamwork, creativity, and communication in group activities is supported by a 2015 study by Greguras, Robie, and Born. They aimed to assess interdependencies among peer ratings to inform how relationship factors influence these ratings. For this purpose, the modified instrument of self and peer rating, which originated with the instrument of Abson (1994), was used, and the result of the participants' self and peer rating showed that the criteria of "cooperation" and "ideas" were significant. Their study defines "cooperation" as a willingness to work together and evidence of good communication skills, which is comparable to this study's criteria in Category 1 (attitude toward group activity, which means showing passion for the group activity by regular, prompt attendance and behaving in a responsible, sincere, and fair way); and Category 3 (communicates with teammates). The criterion of "Ideas" from the study of Greguras, Robie, and Born (2015), and defined as the quality and quantity of ideas, was also consistent with the criteria of Category 4 of this study (Thinks critically and creatively) implying quality of work, initiative, ideas, and creativity.

In conclusion, this study provides evidence that students participating in teamwork most value peers who demonstrate passion for group activities with regular and prompt attendance, and by behaving in a responsible, sincere, and fair manner. The findings also support that having enthusiasm and showing passion for the work at hand is the best welcoming factor than any other in a classroom environment that emphasize an individual's ability with relatively little collaboration. As a result, we may expand our application of the finding to the larger society, where even more collaboration is required.

\section{References}

Abson, D. (1994). "The effects of peer evaluation on the behavior of undergraduate students working in tutorless groups," in Foot, H. C., Howe, C. J. \& Warden, D. A. (Eds.), Group and Interactive Learning. Southhampton: Computational Mechanics.

DeNisi, A.S., Randolph, W.A., \& Blencoe, A.G. (1983). Potential problems with peer ratings. Academy of Management Journal, 26, 457-467.

Diab, R., \& Balaa, L. (2011). Developing detailed rubrics for assessing critique writing: Impact on EFL university students' performance and attitudes. TESOL Journal, 2(1), 52-72.

Felchikov, N. (1986). Product comparisons and process benefits of collaborative peer group and self assessments. Assessment and Evaluation in Higher Education, 11, 146-166.

Greguras, G. J., Robie, C., \& Born, M. P. (2015). Applying the social relations model to self and peer evaluations. Journal of Management Development, 20(6), 508-525.

Hack, C. (2015). Analytic rubrics in higher education: A repository of empirical data. British Journal of Educational Technology, 46(5), 924-927.

Jonsson, A., \& Svingby, G. (2007). The use of scoring rubrics: Reliability, validity, and educational consequences. Educational Research Review, 2, 130144.

Kinne, L. J., Hasenbank, J. F., \& Coffey, D. (2014). Are we there yet? Using rubrics to support progress toward proficiency and model formative assessment. AILACTE Journal, 11(Fall), 109-128.

Kramer, J.F. (1990). Perceived similarity and accuracy of peer ratings. Journal of Educational Psychology, 82, 213-218.

Lejk, M., \& Wyvill, M. (2001). Peer assessment of contributions to a group project: a comparison of 
holistic and category-based approaches. Assessment \& Evaluation in Higher Education, 26(1), 61-72.

Ohland, M.W., Laton, R.A., Loughry, M.L., \& Yuhasz, A.G. (2005). Effects of behavioral anchors on peer evaluation reliability. Journal of Engineering Education, 94(3), 319-326.

Panadero, E., \& Jonsson, A. (2013). The use of scoring rubrics foe formative assessment purposes revisited: A review. Educational Research Review, 9, 129-144.

Powell, S. D. ( 2015). Your introduction to education (3rd). Boston: Pearson.

Strom, P. S., \& Strom, R. D. (2011). Teamwork skills assessment for cooperative learning. Educational Research and Evaluation, 17(4), 233-251.
Reddy, Y. M. \& Angrade, H. (2010). A review of rubric use in higher education. Assessment \& Evaluation in Higher Education, 35(40), 435-448.

Strachan, I. B, \& Wilcox, S. (1996). Peer and self assessment of group work: Developing an effective response to increased enrolment in a third-year course in microclimatology. Journal of Geography in Higher Education, 20, 343-353.

\section{How to cite this article:}

Shin-Il Han (2017) ' Peer Evaluation Rubric Criteria Developed By University Students For Problem-Based Learning ', International Journal of Current Advanced Research, 06(03), pp. 2460-2464. 